\title{
Acute side effects after definitive stereotactic body radiation therapy (SBRT) for patients with clinically localized or locally advanced prostate cancer: a single institution prospective study
}

\author{
Kliton Jorgo ${ }^{1,2}$, Csaba Polgar ${ }^{1,2}$, Gabor Stelczer ${ }^{1,3}$, Tibor Major ${ }^{1,2}$, Laszlo Gesztesi ${ }^{1}$, \\ Peter Agoston ${ }^{1,2}$ \\ ${ }^{1}$ Centre of Radiotherapy, National Institute of Oncology, Budapest, Hungary \\ 2 Department of Oncology, Semmelweis University, Budapest, Hungary \\ ${ }^{3}$ Institute of Nuclear Techniques, Budapest University of Technology and Economy, Budapest, Hungary
}

Radiol Oncol 2021; 55(4): 474-481

Received 10 March 2021

Accepted 30 May 2021

Correspondence to: Dr. Jorgo Kliton, M.D., Ph.D., Centre of Radiotherapy, National Institute of Oncology, Ráth György u. 7-9, Budapest, $\mathrm{H}-1122$, Hungary. E-mail: jorgokliton@gmail.com

Disclosure: No potential conflicts of interest were disclosed.

This is an open access article under the CC BY-NC-ND license (http://creativecommons.org/licenses/by-nc-nd/4.0/).

Background. The aim of the study was to evaluate acute side effects after extremely hypofractionated intensitymodulated radiotherapy (IMRT) with stereotactic body radiation therapy (SBRT) for definitive treatment of prostate cancer patients.

Patients and methods. Between February 2018 and August 2019, 205 low-, intermediate- and high-risk prostate cancer patients were treated with SBRT using "CyberKnife M6" linear accelerator. In low-risk patients 7.5-8 Gy was delivered to the prostate gland by each fraction. For intermediate- and high-risk disease a dose of 7.5-8 Gy was delivered to the prostate and 6-6.5 Gy to the seminal vesicles by each fraction with a simultaneous integrated boost (SIB) technique. A total of 5 fractions (total dose 37.5-40 Gy) were given on every second working day. Acute radiotherapy-related genitourinary (GU) and gastrointestinal (GI) side effects were assessed using Radiation Therapy Oncology Group (RTOG) scoring system.

Results. Of the 205 patients (28 low-, 115 intermediate-, 62 high-risk) treated with SBRT, 203 (99\%) completed the radiotherapy as planned. The duration of radiation therapy was 1 week and 3 days. The frequencies of acute radiotherapy-related side effects were as follows: GU grade $0-17.1 \%$, grade I $-30.7 \%$, grade II $-50.7 \%$, grade III - $1.5 \%$; and GI grade $0-62.4 \%$, grade $1-31.7 \%$, grade $I-5.9 \%$, grade $I I-0 \%$. None of the patients developed grade $\geq 4$ acute toxicity. Conclusions. SBRT with a total dose of 37.5-40 Gy in 5 fractions appears to be a safe and well tolerated treatment option in patients with prostate cancer, associated with slight or moderate early side effects. Longer follow-up is needed to evaluate long-term toxicity and biochemical control.

Key words: prostate cancer; stereotactic radiotherapy; CyberKnife; extreme hypofractionation

\section{Introduction}

Prostate cancer is the most common malignancy among men of European western countries. ${ }^{1}$ In the male population, the incidence of prostate cancer ranks third in Hungary. ${ }^{2}$ Based on the available evidence, treatment options for organ-confined prostate cancer include radical prostatectomy, external beam radiation therapy, brachytherapy, and active follow-up. ${ }^{3-5}$ In a three-arm, phase III, randomized trial (ProtecT), active monitoring, radical prostatectomy and external beam radiation therapy (EBRT) were compared in patients with nonmetastatic, lymph node negative prostate cancer. ${ }^{6,7}$ 
After a median follow-up of 10 years there was no significant difference in prostate cancer specific mortality and overall survival. Significant differences were recognized only in the late side effects regarding bowel-, urinary- and sexual function. Therefore, the toxicity after any curative treatment, and the length and burden of the treatment itself are of great importance. Since Brenner and $\mathrm{Hall}^{8}$ suggested a low $\alpha / \beta$ ratio (1.5) for prostate adenocarcinoma, two treatment options have been investigated for external beam irradiation therapy of prostate cancer patients: moderate hypofractionation (2.2-4Gy/fraction) $)^{9}$ and extreme hypofractionation (3.5-15Gy/fraction). ${ }^{10}$ Three non-inferiority, phase III randomized trials compared conventional fractionation $(\mathrm{CF})$ with moderate hypofractionation $(\mathrm{MH})$, enrolling more than 5500 patients with prostate cancer. ${ }^{11-13}$ At 5-year follow-up these two modalities were shown to be equivalent in terms of tumor control and late side effects, supporting $\mathrm{MH}$ as a standard-of-care. In addition to $\mathrm{MH}$, another method of hypofractionation can be used in the radiation treatment of prostate cancer mainly for patients with low- and intermediate-risk. The extreme hypofractionation (stereotactic body radiation therapy, SBRT) can be performed with either a conventional linear accelerator ${ }^{14,15}$ or a robotic arm (CyberKnife, Accuray Incorporated, Sunnyvale, CA) linear accelerator. ${ }^{16}$ Currently, more and more results are reported on the effectiveness and tolerability of SBRT, predominantly from retrospective and prospective, non-randomized trials. The advantage of SBRT lies in the use of high and precise ablative doses. In addition, overall treatment-time is relatively short (1-2 weeks) compared to conventional or moderately hypofractionated EBRT, and in contrast to surgery or brachytherapy the treatment is non-invasive.

At our institution we have been performing robotic-arm stereotactic radiation treatments since February 2018. The aim of our prospective study was to implement extreme hypofractionated, robotic-arm based SBRT for the treatment of low-, intermediate- and high-risk, lymph node negative prostate cancer patients and to investigate the acute radiotherapy-related side effects.

\section{Patients and methods}

Our prospective study was initiated in February 2018 after approval by our institutional Ethics Committee. Histologically confirmed, low-, intermediate- and high-risk prostate cancer patients were enrolled. Before radiation therapy staging was required (CT scan or pelvic MRI and bone scan). Lymph node or distant metastasis and previous pelvic irradiation were exclusion criteria. Gold fiducial markers were implanted into the prostate of each patient for image-guided radiotherapy (IGRT). The method is described in details in our previous studies. ${ }^{17,18}$ Briefly, patients received $100 \mathrm{mg}$ tramadol and $5 \mathrm{mg}$ metoclopramide intramuscularly half an hour prior to the procedure. Subsequently, patients were laid down in lithotomy position and 4 gold markers were transperineally inserted into the prostate under rectal ultrasound (US) guidance. In the same plane, two markers were placed near the prostate base, two in the apex. For treatment planning, 14-20 days after marker implantation a topometric CT (TOP CT) was performed in supine position using knee fixation support system for immobilization of the legs. Axial images were obtained with $1.25 \mathrm{~mm}$ slice thickness from L1 vertebra to about $3 \mathrm{~cm}$ below the ischial tuberosities. A Metal Artefact Reduction (MAR) corrected CT scan was also acquired to reduce the artefact effects of implanted gold markers. Prior to TOP CT, patients were instructed to have moderately, comfortably filled bladder by drinking 0.5 litre of water (after having it emptied) half an hour prior to $\mathrm{CT}$ and an empty rectum. In case of habitual constipation light laxative was recommended. In our study, patients were treated according to $\mathrm{D}^{\prime}$ Amico's classification in 3 risk groups. ${ }^{19}$ In low-risk patients the clinical target volume for ptostate (CTVpros) was the prostate gland. For intermediate-risk two clinical target volumes were created. CTVpros was the same as above. The prostate and seminal vesicles CTV (CTVpsv) was generated by $5 \mathrm{~mm}$ expansion of CTVpros in all directions except posteriorly at the prostate-rectum interface + proximal $1 \mathrm{~cm}$ of the seminal vesicles. For high-risk patients CTVpros was the same as above. CTVpsv was defined by $5 \mathrm{~mm}$ expansion of CTVpros in all directions except posteriorly + proximal $2 \mathrm{~cm}$ of seminal vesicles (in case of cT3b the entire seminal vesicles were included).

Planning target volumes (PTVpros, PTVpsv) were formed from CTVs with $3 \mathrm{~mm}$ extensions in each direction. Depending on the performance status and age of the patients for low-risk patients 7.5-8 Gy fraction dose was applied to PTVpros. In case of intermediate- and high-risk disease 7.5-8 Gy fraction dose to PTVpros and a 6-6.5 Gy fraction dose to PTVpsv, with a simultaneous integrated boost (SIB) technique was given. A total of 5 fractions (total dose for prostate 37.5-40 Gy) were 
TABLE 1. Dose constraints for organs at risk

\begin{tabular}{ll}
\hline Rectum & $\mathrm{D} 0.04 \mathrm{ccm}<38 \mathrm{~Gy}, \mathrm{D} 20 \mathrm{ccm}<25 \mathrm{~Gy}$ \\
Bladder & $\mathrm{V} 26 \%<65 \%$ \\
\hline Bladder wall & $\mathrm{D} 0.04 \mathrm{ccm}<44 \mathrm{~Gy}$ \\
\hline Sigma & $\mathrm{D} 0.04 \mathrm{ccm}<44 \mathrm{~Gy}, \mathrm{~V} 30 \mathrm{~Gy}<1 \mathrm{ccm}$ \\
Small intestine & $\mathrm{D} 0.04 \mathrm{ccm}<35 \mathrm{~Gy}, \mathrm{~V} 30 \mathrm{~Gy}<1 \mathrm{ccm}, \mathrm{D} 5 \mathrm{ccm}<19.5 \mathrm{~Gy}$ \\
Hip joint & $\mathrm{V} 40 \%<5 \%, \mathrm{D} 10 \mathrm{ccm}<30 \mathrm{~Gy}$ \\
\hline Testicle & $\mathrm{D} 20 \%<2 \mathrm{~Gy}$ \\
\hline Penis root & $\mathrm{V} 29.5 \mathrm{~Gy}<50 \%, \mathrm{D} 0.04 \mathrm{ccm}<50 \mathrm{~Gy}$ \\
\hline
\end{tabular}

Dxxccm or Dxx\% = an absolute dose value covering exactly XX ccm or XX \% of the given organ at risk; $V x x G y$ or $V x x \%=$ volume of a given OAR receiving $X X$ Gy or $X X \%$ of the prescribed dose

administered every other day. The dose constraints for the organs at risk are detailed in Table 1.

The treatment plans were prepared using the Accuray Precision 1.1.1.1 planning system. The dose was prescribed to the $80-85 \%$ isodose curve. Dose-coverage requirement for target volumes (PTVpros, PTVpsv) was V100\% > 95\%. Irradiation from non-coplanar fields was performed using a multileaf collimator with a CyberKnife M6 (Accuray, Sunyvale, CA) robotic accelerator. Based on planning CT digitally reconstructed X-ray images (DRRs) from 45 and 315 degrees were generated and served as reference images for patient alignment. At the start of the treatment, x-rays of the same directions were taken showing the position of gold markers in the prostate. Subsequently, the images were matched by a software and the inaccuracy of the alignment was determined based on the position of the markers in three directions (lateral, longitudinal, vertical) and rotation (roll, pitch, rotation). If the inaccuracy of the set-up was greater than $10 \mathrm{~mm}$ or 3 degrees, we automatically corrected the deviation by moving the treatment couch. In case of a smaller set-up inaccuracy, the corrections were applied by the robotic arm during operation. This verification course was repeated every 20-60 seconds during the treatments, depending on the intra-fractional prostate movements. Patients were followed-up during radiation treatment, after the second and last fractions, then every 3 months. In the present study, maximal acute toxicity data were reported up to the last day of radiotherapy and 3 months after treatment. Acute genitourinary (GU) and gastrointestinal (GI) side effects were classified according to the Radiation Therapy Oncology Group (RTOG) scoring system (Table 2.). ${ }^{20}$ In Statistica software (StatSoft, Inc., USA) Spearman rank order tests were used to evaluate the correlations between risk groups, total dose (37.5 Gy vs. $40 \mathrm{~Gy}$ ), age of patients, hormonal therapy, volume of CTVpros, PTVpros, CTVpsv, PTVpsv, dosimetric parameters of rectum (D0.04ccm, D20ccm), bladder (V26Gy, D0.04ccm), pre-treatment transurethral resection of prostate (TURP) and acute GI, GU side effects. Statistical significance was set at $p<0.05$.

\section{Results}

Between February 2018 and August 2019, 205 patients with prostate cancer were treated definitively with SBRT. Median follow-up was 8 months. The mean age of the patients was 71 years (range: 58-78 years). The patient, tumor and treatment characteristics are summarized in Table 3. No periand postoperative complications were observed after implantation of the gold markers. 179 patients (87.3\%) received a total dose of $40 \mathrm{~Gy}$ (8 Gy/

TABLE 2. Radiation Therapy Oncology Group acute radiation morbidity scoring scheme ${ }^{20}$

\begin{tabular}{|c|c|c|c|c|c|}
\hline Organ tissue & Grade 0 & Grade 1 & Grade 2 & Grade 3 & Grade 4 \\
\hline $\begin{array}{l}\text { Gastrointestinal } \\
\text { including pelvis }\end{array}$ & $\begin{array}{l}\text { No } \\
\text { change }\end{array}$ & $\begin{array}{l}\text { Increased frequency } \\
\text { or change in quality } \\
\text { of bowel habits not } \\
\text { requiring medication/ } \\
\text { rectal discomfort not } \\
\text { requiring analgesics }\end{array}$ & $\begin{array}{l}\text { Diarrhea requiring } \\
\text { parasympatholytic } \\
\text { drugs/mucous } \\
\text { discharge not } \\
\text { necessitating } \\
\text { sanitary pads/rectal } \\
\text { or abdominal pain } \\
\text { requiring analgesics }\end{array}$ & $\begin{array}{l}\text { Diarrhea requiring } \\
\text { parenteral support/severe } \\
\text { mucous or blood discharge } \\
\text { necessitating sanitary } \\
\text { pads/abdominal distention } \\
\text { (flat plate radiograph } \\
\text { demonstrates distended } \\
\text { bowel loops) }\end{array}$ & $\begin{array}{l}\text { Acute or subacute } \\
\text { obstruction, fistula or } \\
\text { perforation; Gl bleeding } \\
\text { requiring transfusion; } \\
\text { abdominal pain or } \\
\text { tenesmus requiring tube } \\
\text { decompression or bowel } \\
\text { diversion }\end{array}$ \\
\hline Genitourinary & $\begin{array}{l}\text { No } \\
\text { change }\end{array}$ & $\begin{array}{l}\text { Frequency of } \\
\text { urination or nocturia } \\
\text { twice pretreatment } \\
\text { habit/dysuria, } \\
\text { urgency not requiring } \\
\text { medication }\end{array}$ & $\begin{array}{l}\text { Frequency of urination } \\
\text { or nocturia that is } \\
\text { less frequent than } \\
\text { every hour. Dysuria, } \\
\text { urgency, bladder } \\
\text { spasm requiring local } \\
\text { anesthetic }\end{array}$ & $\begin{array}{l}\text { Frequency with urgency } \\
\text { and nocturia hourly or } \\
\text { more frequently/dysuria, } \\
\text { pelvis pain or bladder } \\
\text { spasm requiring regular, } \\
\text { frequent narcotic/gross } \\
\text { hematuria with/ without } \\
\text { clot passage }\end{array}$ & $\begin{array}{l}\text { Hematuria requiring } \\
\text { transfusion/acute } \\
\text { bladder obstruction } \\
\text { not secondary to clot } \\
\text { passage, ulceration, or } \\
\text { necrosis }\end{array}$ \\
\hline
\end{tabular}


fraction[fx]) and 26 patients (12.7\%) 37.5 Gy (7.5 $\mathrm{Gy} / \mathrm{fx}$ ). Dose volumes parameters of the rectum and bladder, volumes and dose coverage of the prostate and seminal vesicles clinical- and planning target volumes (CTVpros, CTVpsv, PTVpros, PTVpsv) of patients are summarized in Tables 4 and 5 . The duration of radiation treatment was 1 week and 3 days ( 3 fractions per week). The delivery of a fraction took $25-45$ minutes, depending on the complexity of the treatment plan and the frequency of verification X-rays. The frequency of control imaging was related to intra-fractional prostate movements. During control imaging, all the implanted gold markers were clearly visible with a sufficient distance from each other. No marker migration was detected.

In our patients, acute grade 3 side effects were rare, most of acute toxicity resolved spontaneously or with the administration of medications. 202 patients $(98.5 \%)$ completed radiation therapy at the planned dose and did not require a therapeutic interruption due to radiotherapy-related adverse events. Three patients (1.5\%) had to have an urethral catheter inserted due to a complete retention of urine. One of them underwent transurethral resection of prostate (TURP) two months after treatment. After that the radiation therapy was completed with conventional fractionation. The second one refused to complete the radiation treatment, he is currently receiving hormone therapy. The third patient had a urethral catheter only for one week, after that urinary complaints resolved by using $\alpha$-blockers and the treatment was completed with the planned dose. Acute grade 2 and $3 \mathrm{GU}$ toxicity was reported in $104(50.7 \%)$ and $3(1.5 \%)$ cases, respectively. Acute grade 2 and 3 GI adverse events occurred in $12(5.9 \%)$ and $0(0 \%)$ patients, respectively. None of the patients developed $\geq$ grade 4 acute side effect. At 3 months after the treatment the incidence of grade 2 and 3 GI toxicity was $0.5 \%$ $(\mathrm{n}=1)$ and $0 \%(\mathrm{n}=0)$, while grade 2 and $3 \mathrm{GU}$ side effects occurred in $9.7 \%(n=20)$ and $1 \%(n=2)$ of the patients, respectively. Frequency of radiotherapy-related toxicities according to the RTOG grading system during radiation therapy and 3 months after treatment are detailed in Table 6. Acute side effects at the end of radiotherapy according to the risk groups are shown in Table 7.

No statistical correlation was detected between risk groups, age of patients, hormone therapy, pretreatment TURP and acute GI, GU side effects.

Significant correlation was observed between acute $\leq 2 \mathrm{GU}$ toxicities and pre-treatment TURP, delivered dose, volumes of CTVpros, CTVpsv,
TABLE 3. Patient, tumour and treatment characteristics

\begin{tabular}{|c|c|}
\hline Characteristic & Number (\%) \\
\hline \multicolumn{2}{|l|}{ Age (years) } \\
\hline Median & 73 \\
\hline Range & $54-85$ \\
\hline \multicolumn{2}{|l|}{ T stage } \\
\hline $\mathrm{Tl}$ & 45 (22\%) \\
\hline $\mathrm{T} 2 \mathrm{a}$ & 35 (17.1\%) \\
\hline $\mathrm{T} 2 \mathrm{~b}$ & $52(25.3 \%)$ \\
\hline $\mathrm{T} 2 \mathrm{C}$ & 58 (28.3\%) \\
\hline T3a & $7(3.4 \%)$ \\
\hline T3b & 8 (3.9\%) \\
\hline \multicolumn{2}{|l|}{ Gleason score } \\
\hline$\leq 6$ & 60 (29.3\%) \\
\hline 7 & $108(52.7 \%)$ \\
\hline$\geq 8$ & $37(17 \%)$ \\
\hline \multicolumn{2}{|l|}{ Initial PSA ${ }^{1}$} \\
\hline Median & 15 \\
\hline Range & $2-137$ \\
\hline$<10$ & 108 (52.7\%) \\
\hline $10-20$ & $67(32.7 \%)$ \\
\hline$\geq 20$ & 30 (14.6\%) \\
\hline \multicolumn{2}{|l|}{ Risk groups } \\
\hline Low & 23 (11.2\%) \\
\hline Intermediate & $120(58.6 \%)$ \\
\hline High & $62(30.2)$ \\
\hline \multicolumn{2}{|l|}{ Hormonal therapy } \\
\hline No & 88 (42.9\%) \\
\hline Short ( $\leq 6$ months) & $61(29.8 \%)$ \\
\hline Long (> 6 months) & 56 (27.3\%) \\
\hline TURP2 $^{2}$ before $S B R T^{3}$ & $22(10.7 \%)$ \\
\hline \multicolumn{2}{|l|}{ Total dose } \\
\hline $37.5 \mathrm{~Gy}^{4}$ & $26(12.7 \%)$ \\
\hline $40 \mathrm{~Gy}$ & $179(87.3 \%)$ \\
\hline
\end{tabular}

${ }^{1} \mathrm{PSA}=$ prostate specific antigen, ${ }^{2 T U R P}=$ transurethral resection of the prostate; ${ }^{3 S B R T}=$ stereotactic body radiation therapy, ${ }^{4} \mathrm{G} y=$ Gray

TABLE 4. Dose-volume parameters of rectum and bladder with constraints

\begin{tabular}{|c|c|c|c|}
\hline Organs at risks & Dose constrain & Mean & Median (range) \\
\hline \multicolumn{4}{|l|}{ Rectum } \\
\hline D $0.04 \mathrm{~cm}^{3}$ (Gy) & 38 & 37.6 & $37.8(32.3-41.5)$ \\
\hline D $20 \mathrm{~cm}^{3}$ (Gy) & 26 & 18.8 & $19.2(8.0-27.6)$ \\
\hline \multicolumn{4}{|l|}{ Bladder wall } \\
\hline D $0.04 \mathrm{~cm}^{3}$ (Gy) & 44 & 40.4 & $40.4(30.7-48.6)$ \\
\hline D $15 \mathrm{~cm}^{3}$ (Gy) & 18.3 & 29.1 & $18.9(6.9-29.1)$ \\
\hline \multicolumn{4}{|l|}{ Bladder } \\
\hline V 26Gy (\%) & 65 & 9.1 & $7.3(0.9-41.9)$ \\
\hline
\end{tabular}

$D x x \mathrm{Cm}^{3}$ or $\mathrm{Dxx} \%=$ an absolute dose value covering exactly $\mathrm{XX} \mathrm{cm}^{3}$ or $\mathrm{XX} \%$ of the given organ at risk; $V x x G y$ or $V x x \%=$ volume of a given OAR receiving $X X$ Gy or $X X \%$ of the prescribed dose 
TABLE 5. Median volumes and dose coverages of prostate and seminal vesicles clinical- and planning target volumes (CTVpros, CTVpsv, PTVpros, PTVpsv) of 205 prostate cancer patients treated with stereotactic radiation therapy

\begin{tabular}{|c|c|c|c|c|}
\hline Volume, $\mathrm{cm}^{3}$ (range) & $\begin{array}{c}52.1 \\
(15.9-134.7)\end{array}$ & $\begin{array}{c}70.6 \\
(25.1-166.6)\end{array}$ & $\begin{array}{c}80.4 \\
(30.8-208.5)\end{array}$ & $\begin{array}{c}108.1 \\
(45.4-259.3)\end{array}$ \\
\hline
\end{tabular}

TABLE 6. Acute toxicities after prostate and seminal vesicles intensity-modulated, stereotactic irradiation with SIB technique ( $N=205)$

\begin{tabular}{lccc}
\hline Toxicity & Grade & $\begin{array}{c}\text { Toxicity at the end } \\
\text { of treatment } \\
\mathbf{N}=\mathbf{2 0 5}(\%)\end{array}$ & $\begin{array}{c}\text { Toxicity } \mathbf{3} \text { months } \\
\text { after treatment } \\
\mathbf{N}=\mathbf{2 0 5}(\%)\end{array}$ \\
\hline \multirow{3}{*}{ Gastrointestinal } & 0 & $128(62.4)$ & $195(95)$ \\
& 2 & $65(31.7)$ & $9(4.5)$ \\
\hline Genitourinary & 3 & $12(5.9)$ & $1(0.5)$ \\
& 0 & $0(0)$ & $0(0)$ \\
& 2 & $35(17.1)$ & $153(74.6)$ \\
& 2 & $63(30.7)$ & $30(14.7)$ \\
\hline
\end{tabular}

TABLE 7. Acute side effects at the end of radiation therapy according to the risk groups

\begin{tabular}{lcccc}
\hline Toxicity & Grade & $\begin{array}{c}\text { Low risk } \\
\mathbf{N}=\mathbf{2 3}(\%)\end{array}$ & $\begin{array}{c}\text { Intermediate risk } \\
\mathbf{N}=\mathbf{1 2 0}(\%)\end{array}$ & $\begin{array}{c}\text { High risk } \\
\mathbf{N}=\mathbf{6 2}(\%)\end{array}$ \\
\hline \multirow{3}{*}{ Gastrointestinal } & 0 & $8(35)$ & $83(69)$ & $37(60)$ \\
& 1 & $14(61)$ & $29(24)$ & $22(35)$ \\
& 2 & $1(4)$ & $8(7)$ & $3(5)$ \\
Genitourinary & 3 & $0(0)$ & $0(0)$ & $0(0)$ \\
& 0 & $1(4)$ & $26(74.6)$ & $8(13)$ \\
& 1 & $10(43)$ & $25(14.7)$ & $28(45)$ \\
& 2 & $12(54)$ & $66(9.7)$ & $26(42)$ \\
\hline
\end{tabular}

PTVpros, PTVpsv, bladder V26Gy, D0.04ccm ( $\mathrm{p}<$ $0.05)$. No other parameters had a significant correlation with toxicity.

\section{Discussion}

Organ confined prostate cancer is usually treated with EBRT. Data from phase III, randomized studies support $\mathrm{MH}$ to be non-inferior to CF. Recently a great interest is shown in SBRT. According to surveys, the biggest disadvantage of $\mathrm{CF}$ is the long treatment time..$^{21}$ Due to the low fraction number, on our opinion SBRT may have the potential to increases patient satisfaction with treatment. This is supported by the fact that it is a non-invasive treatment option. ${ }^{22}$ Compared with conventional EBRT stereotactic irradiation treatment of prostate cancer seems to be the most cost-effective management option. ${ }^{23}$ Also taking into account the radiobiological benefit of hypofractionation, the acceptance of extreme hypofractionation with SBRT is increasing in medical communities.

Recently, Brand et al..$^{24}$ first reported acute toxicity from a randomized, non-inferiority, phase III study (PACE-B). A total of 847 low- and intermediate risk patients were randomly assigned to $\mathrm{CF} /$ $\mathrm{MH}$ (78 Gy in 39 fractions/62 Gy in 20 fractions) or SBRT (36.25 Gy in 5 fractions). The frequency of acute grade 1, 2, 3 and $4 \mathrm{GU}$ toxicity in the $\mathrm{CF} / \mathrm{MH}$ arm versus the SBRT arm was 59\%, 26\%, $1 \%$ and < $1 \%$, versus $57 \%, 21 \%, 2 \%$ and $<1 \%$, respectively. Acute grade 1,2,3 and 4 GI side effects occurred in $\mathrm{CF} / \mathrm{MH}$ arm in $61 \%, 11 \%, 1 \%$ and $0 \%$ versus in the SBRT arm in $53 \%, 10 \%,<1 \%$ and $0 \%$, respectively. These results suggest that shortened treatment time (SBRT) does not increase neither acute GI nor GU toxicity.

Immediately after that, the second phase III, non-inferiority, randomized trial (HYPO-RT-PC) was published comparing CF radiotherapy with SBRT in intermediate- and high-risk prostate cancer patients. ${ }^{25}$ In contrast with PACE-B trial in HYPO-RT-PC patients were treated mostly with 3D conformal technique. In the SBRT arm acute grade $1-2$ and 3 GU toxicity was recorded in $48 \%$ and $5 \%$ of the patients. Acute grade 1-2 and 3 GI side effects occurrence was $51 \%$ and $1 \%$. Acute GU toxicity was significantly worse in the SBRT arm, but no significant difference was recorded in acute GI or late GU/GI toxicities and failure free survival ( $84 \%$ vs. $84 \%$ ) at 5-year median follow up, conforming the non-inferiority of SBRT to CF radiotherapy.

In the last 10-15 years several prospective and retrospective studies reported low rates of severe 
TABLE 8. SUmmary of acute genitourinary (GU) and gastrointestinal (GI) toxicities published in trials using SBRT for prostate cancer treatment

\begin{tabular}{|c|c|c|c|c|c|c|}
\hline Study & No. of patients & Dose & Grade 1-2 GU (\%) & Grade $\geq 3$ GU (\%) & Grade 1-2 GI (\%) & Grade $\geq 3 \mathrm{GI}(\%)$ \\
\hline Madsen, $2007^{26}$ & 40 & $6.7 \mathrm{~Gy} \times 5 \mathrm{fx}$ & 49 & 2.5 & 39 & 0 \\
\hline Katz, $2010^{27}$ & 304 & $7 / 7.25 \mathrm{~Gy} \times 5 \mathrm{fx}$ & 79 & 0 & 78 & 0 \\
\hline Boike, $2011^{28}$ & 45 & $9.5 / 10 \mathrm{~Gy} \times 5 \mathrm{fx}$ & 51 & 0 & 55 & 0 \\
\hline Freeman, $2011^{29}$ & 41 & $7 / 7.25 \mathrm{~Gy} \times 5 \mathrm{fx}$ & 32 & 2.5 & 16 & 0 \\
\hline Loblaw, $2013^{15}$ & 84 & 7 Gy $x 5 \mathrm{fx}$ & 88 & 1 & 77 & 0 \\
\hline Bolzicco, $2013^{32}$ & 100 & 7 Gy x 5 fx & 46 & 0 & 45 & 0 \\
\hline Oliai, $2013^{33}$ & 70 & $7-7.4 \mathrm{~Gy} \times 5 \mathrm{fx}$ & 63 & 4 & 26 & 3 \\
\hline Mantz, $2014^{34}$ & 102 & $8 \mathrm{~Gy} \times 5 \mathrm{fx}$ & 58 & 2 & 0 & 0 \\
\hline Brand, $2019^{124}$ & 415 & 7.25 Gy x $5 \mathrm{fx}$ & 78 & 3 & 63 & 1 \\
\hline 'Widmark, $2019^{25}$ & 589 & $6.1 \mathrm{~Gy} \times 7 \mathrm{fx}$ & 48 & 5 & 51 & 1 \\
\hline Present study & 205 & $7.5 / 8 \mathrm{~Gy} \times 5 \mathrm{fx}$ & 81 & 1.5 & 38 & 0 \\
\hline All studies & 2319 & $\begin{array}{l}\text { Total dose: } 33.5-50 \text { Gy } \\
\text { Number of fxs: } 5-7\end{array}$ & $32-88$ & $0-5$ & $0-78$ & $0-3$ \\
\hline
\end{tabular}

1 = phase III, randomized trial; $\mathrm{fx}=$ fraction

acute toxicity with the use of SBRT for extreme hypofractionation applying commonly a total of 5 fractions with 7-8 Gy fraction doses. ${ }^{15,26-37}$ The frequency of acute $\geq$ grade $3 \mathrm{GU}$ and GI side effects was $0-5 \%$ and $0-3 \%$, respectively (Table 8 ).

In our phase II prospective study, we reported acute toxicity after extremely hypofractionated, intensity-modulated radiotherapy with SBRT technique for prostate cancer patients. Patients with low- $(\mathrm{n}=23)$, intermediate- $(\mathrm{n}=120)$ and high-risk $(n=62)$ prostate cancer patients were treated with SBRT, in every second working day and 7.5-8 Gy to the prostate and 6-6.5 Gy to the seminal vesicles was delivered with SIB technique, in a total of 5 fractions (total dose 37.5-40 Gy). Of the 205 patients treated, grade 1-2 GU and GI side effects occurred in $81 \%$ and $38 \%$. Three months after treatment, these side effects were present only in $24 \%$ and $5 \%$, respectively. The frequency of grade $3 \mathrm{GU}$ toxicity was $1.5 \%$. In the case of extreme hypofractionation, due to pelvic anatomy and radiation sensitivity, the most critical organ at risk is the rectum. In our study, no grade 3 GI acute side effect was observed, and at 3 months after irradiation 95\% of patients had no gastrointestinal complaints (GI
Gr.0). Our results regarding acute toxicity are similar to those of reported in the literature using similar total doses and fractionation schemes (Table 8).

Because of the lack of prospective data and paucity of the literature, the effect of pre-treatment TURP on side effects after SBRT currently needs to be investigated. One of the most important data on this issue was reported by Murthy et al. ${ }^{38}$ Fifty prostate cancer patients with pre-treatment TURP were propensity score matched to a similar nonTURP cohort. No significant difference was recorded regarding acute $\geq$ grade $2 \mathrm{GU}$ side effects $(8 \%$ vs. $6 \%, \mathrm{P}=0.45)$. Wang et al. ${ }^{39}$ concluded that a pre-treatment TURP increases the incidence of urinary incontinence and worsens urinary quality of life. In our patient cohort 22 patients (10.7\%) underwent prior TURP. There was no difference between TURP and non-TURP patients with respect to acute GU toxicity. However, the impact of prior TURP on GU toxicity after SBRT is still controversial.

Based on our statistical analyses, a significant correlation was shown between the volume of the prostate gland (CTVpros), CTVpsv, PTVpros, PTVpsv and acute GU toxicities. These findings draw our attention to the fact that a large volume 
of prostate or a large safety margin can affect GU side effects. According several studies, patients with a large prostate volume before SBRT experienced worse GU side effects..$^{40-42}$ Katz et al.$^{41}$ reported in 336 patients that the rate of late grade 2 and 3 GU toxicity was $15 \%$ versus $8 \%$ in patients with prostate volume greater than versus less than 60 $\mathrm{cm}^{3}$, respectively.

Three large randomized trials are ongoing to establish SBRT as the preferred standard option for localized disease. The NRG GU-005 trial (NCT03367702) compares SBRT (36.25 Gy in 5 fractions) with moderately hypofractionated radiation therapy (70 Gy in 28 fractions) and is designed to confirm the superiority of SBRT. The PACE series trials (A-C) aim to assess whether SBRT (36.25 Gy in 5 fractions) offers a therapeutic benefit over prostatectomy or conventional radiation therapy (78 Gy in 39 fractions) for patients with localized disease (NCT01584258). The MIRAGE trial is randomized phase III trial comparing MRI-guided SBRT (40 Gy in five fractions) with CT-guided SBRT for organ-confined prostate cancer. The purpose of this study is to demonstrate the benefit of using MRI-guided SBRT in terms of acute grade $\geq 2$ GU side effects when compared to CT-guided SBRT (NCT04384770).

One limitation of our single arm phase II prospective study is that SBRT was not compared with $\mathrm{CF}$ or $\mathrm{MH}$ in a randomized manner. Another factor slightly reducing the value of this study is that the side effects were graded by the physician, which increases the subjectivity of the assessment and may differ in the proportion and severity of the patientreported toxicities. Further follow-up is needed to validate late side effects and tumor control.

At our institute, treatment with CF (2 Gy/day) or MH (2.5 Gy/day) takes 39 or 28 working days. During SBRT, radiation treatment can be delivered in less than 2 weeks, thus reducing the total radiation treatment time by up to 6 weeks. Routine application of SBRT can reduce waiting time and total treatment time. Shorter treatment times are also beneficial for patients.

\section{Conclusions}

The treatment of clinically localized prostate cancer patients using SBRT with 7.5-8 Gy fractions delivered every other working day, with a total dose of 37.5-40 Gy, appears to be a safe treatment and can be introduced into daily routine. Acute GI and GU side effects were moderate, with rare grade 3
GU side effects and no acute grade 3-4 GI side effects. In the majority of cases, toxicities resolved spontaneously by 3 months after treatment. The total treatment time with SBRT is more than 6 weeks shorter compared to EBRT with conventional fractionation.

\section{References}

1. Bray F, Ferlay J, Soerjomataram I, Siegel RL, Torre LA, Jemal A. Global cancer statistics 2018: GLOBOCAN estimates of incidence and mortality worldwide for 36 cancers in 185 countries. Cancer J Clin 2018; 68: 394-24. doi: 10.3322/ caac. 21492

2. Ferlay J, Colombet M, Soerjomataram I, Dyba T, Randi G, Bettio M, et al. Cancer incidence and mortality patterns in Europe: estimates for 40 countries and 25 major cancers in 2018. Eur J Cancer 2018; 103: 356-87. doi: 10.1016/j.ejca.2018.07.005

3. Attard G, Parker C, Eeles R, Schröder F, Tomlins S, Tannock I, et al. Prostate cancer. Lancet 2016; 387: 70-82. doi: 10.1016/S0140-6736(14)61947-4

4. Torre LA, Siegel RL, Ward EM, Jemal A. Global cancer incidence and mortality rates and trends - an update. Cancer Epidemiol Biomarkers Prev 2016; 25: 16-27. doi: 10.1158/1055-9965

5. Heidenreich A, Bastian PJ, Bellmunt J, Bolla M, Joniau S, van der Kwast T, et al. EAU guidelines on prostate cancer. Part 1: screening, diagnosis, and local treatment with curative intent-update 2013. Eur Urol 2014; 65: 124-37. doi: 10.1016/j.eururo.2013.09.046

6. Donovan JL, Hamdy FC, Lane JA, Mason M, Metcalfe C, Walsh E, et al. Patient-reported outcomes after monitoring, surgery, or radiotherapy for prostate cancer. N Engl J Med 2016; 375: 1425-37. doi: 10.1056/ NEJMoa1606221

7. Hamdy FC, Donovan JL, Lane JA. 10-year outcomes after monitoring, surgery, or radiotherapy for localized prostate cancer. N Engl J Med 2016; 375: 1415-24. doi: 10.1056/NEJMoa1606220

8. Brenner DJ, Hall EJ. Fractionation and protraction for radiotherapy of prostate carcinoma. Int J Radiat Oncol Biol Phys 1999; 43: 1095-101. doi: 10.1016/s0360-3016(98)00438-6

9. Arcangeli S, Greco C. Hypofractionated radiotherapy for organ-confined prostate cancer: is less more? Nat Rev Urol 2016; 13: 400-8. doi: 10.1038/ nrurol.2016.106

10. Zaorsky NG, Studenski MT, Dicker AP, Gomella L, Den R. Stereotactic body radiation therapy for prostate cancer: is the technology ready to be the standard of care? Cancer Treat Rev 2013; 39: 212-8. doi: 10.1016/j. ctrv.2012.10.003

11. Dearnaley D, Syndikus I, Mossop H, Bidmead M, Bloomfield D, Clark C, et al. Conventional versus hypofractionated high-dose intensity-modulated radiotherapy for prostate cancer: 5-year outcomes of the randomised, non-inferiority, phase 3 CHHiP trial. Lancet Oncol 2016; 17: 1047-60. doi: 10.1016/S1470-2045(16)30102-4

12. Catton CN, Lukka H, Gu CS, Martin J, Supiot S, Chung P, et al. Randomized trial of a hypofractionated radiation regimen for the treatment of localized prostate cancer. J Clin Oncol 2017; 35: 1884-90. doi: 10.1200/ JCO.2016.71.7397

13. Lee WR, Dignam JJ, Amin MB, Bruner D, Low D, Swanson G, et al Randomized phase III noninferiority study comparing two radiotherapy fractionation schedules in patients with low-risk prostate cancer. J Clin Oncol 2016; 34: 2325-32. doi: 10.1200/JCO.2016.67.0448

14. Aluwini S, van Rooij P, Hoogeman M, Kirkels W, Kolkman-Deurloo I, Bangma C. Stereotactic body radiotherapy with a focal boost to the MRI-visible tumor as monotherapy for low- and intermediate-risk prostate cancer: early results. Radiat Oncol Lond Eng/ 2013; 8: 84. doi: 10.1186/1748-717X-8-84

15. Loblaw A, Cheung P, D’Alimonte L, Deabreu A, Mamedov A, Zhang L, et al. Prostate stereotactic ablative body radiotherapy using a standard linear accelerator: toxicity, biochemical, and pathological outcomes. Radiother Oncol J Eur Soc Ther Radiol Oncol 2013; 107: 153-8. doi: 10.1016/j.radonc.2013.03.022 
16. King CR, Brooks JD, Gill H, Presti Jr J. Long-term outcomes from a prospective trial of stereotactic body radiotherapy for low-risk prostate cancer. Int J Radiat Oncol Biol Phys 2012; 82: 877-82. doi: 10.1016/j.jijrobp.2010.11.054

17. Jorgo K, Ágoston P, Szabó Z, Major T, Polgár Cs. [Use of gold radionuclide markers implanted into the prostate for image-guided radiotherapy in prostate cancer: side effects caused by the marker implantation]. [Hungarian] Magy Onkol 2014; 58: 182-87.

18. Jorgo K, Agoston P, Major T, Takácsi-Nagy Z, Polgár Cs. Transperineal gold marker implantation for image-guided external beam radiotherapy of prostate cancer. A single institution, prospective study. Strahlenther Onkol 2017; 193: 452-58. doi: 10.1007/s00066-017-1104-2.

19. D’Amico AV, Moul J, Carroll PR, Sun L, Lubeck D, Chen M. Cancer-specific mortality after surgery or radiation for patients with clinically localized prostate cancer managed during the prostate-specific antigen era. J Clin Oncol 2003; 21: 2163-72. doi: 10.1200/JCO.2003.01.075

20. Cox JD, Stetz J, Pajak TF. Toxicity criteria of the Radiation Therapy Oncology Group (RTOG) and the European Organization for Research and Treatment of Cancer (EORTC). Int J Radiat Oncol Biol Phys 1995; 30: 1341-46. doi: 10.1016/0360-3016(95)00060-C

21. Holmboe ES, Concato J. Treatment decisions for localized prostate cancer: asking men what's important. J Gen Intern Med 2000; 15: 694-701. doi: 10.1046/j.1525-1497.2000.90842.x

22. Dandapani SV, Sanda MG. Measuring health-related quality of life consequences from primary treatment for early-stage prostate cancer. Semin Radiat Oncol 2008; 18: 67-72. doi: 10.1016/j.semradonc.2007.10.001

23. Hodges JC, Lotan Y, Boike TP, Benton R, Barrier A, Timmerman R. Costeffectiveness analysis of SBRT versus IMRT: an emerging initial radiation treatment option for organ-confined prostate cancer. Am J Manag Care 2012; 18: e186-93. doi: 10.1200/JOP.2012.000548

24. Brand DH, Tree AC, Ostler P, van der Voet H, Loblaw A, Chu W, et al. Intensity-modulated fractionated radiotherapy versus stereotactic body radiotherapy for prostate cancer (PACE-B): acute toxicity findings from an international, randomised, open-label, phase 3, non-inferiority trial. Lancet Oncol 2019; 20: 1531-43. doi: 10.1016/S1470-2045(19)30569-8

25. Widmark A, Gunnlaugsson A, Beckman L, Thellenberg-Karlsson C, Hoyer M, Lagerlund $\mathrm{M}$, et al. Ultra-hypofractionated versus conventionally fractionated radiotherapy for prostate cancer: 5-year outcomes of the HYPO-RT-PC randomised, non-inferiority, phase 3 trial. Lancet 2019; 394: 385-95. doi: 10.1016/S0140-6736(19)31131-6

26. Madsen BL, Hsi RA, Pham HT, Fowler J, Esagui L, Corman J. Stereotactic hypofractionated accurate radiotherapy of the prostate (SHARP), 33.5Gy in five fractions for localized disease: first clinical trial results. Int J Radiat Oncol Biol Phys 2007; 67: 1099-105. doi: 10.1016/j.jjrobp.2006.10.050

27. Katz AJ, Santoro M, Ashley R, Diblasio F, Witten M, et al. Stereotactic body radiotherapy for organ-confined prostate cancer. BMC Urol 2010; 10: 1. doi: $10.1186 / 1471-2490-10-1$

28. Boike TP, Lotan $Y$ Cho LC, Brindle J, DeRose $P$ Xie $X$, et al. Phase I doseescalation study of stereotactic body radiation therapy for low- and intermediate-risk prostate cancer. J Clin Oncol 2011; 29: 2020-26. doi: 10.1200/ JCO.2010.31.4377

29. Freeman $D E$, King $C R$. Stereotactic body radiotherapy for low-risk prostate cancer: five-year outcomes. Radiat Oncol 2011; 6: 3. doi: 10.1186/1748717X-6-3

30. Jabbari S, Weinberg VK, Kaprealian T, Hsu I, Ma L, Chuang C, et al. Stereotactic body radiotherapy as monotherapy or post-external beam radiotherapy boost for prostate cancer: technique, early toxicity, and PSA response. Int J Radiat Oncol Biol Phys 2012; 82: 228-34. doi: 10.1016/j. ijrobp.2010.10.026

31. McBride SM, Wong DS, Dombrowski JJ, Harkins B, Tapella P, Hanscom H, et al. Hypofractionated stereotactic body radiotherapy in low-risk prostate adenocarcinoma: preliminary results of a multi-institutional phase 1 feasibility trial. Cancer 2012; 118: 3681-90. doi: 10.1002/cncr.26699

32. Bolzicco G, Favretto MS, Satariano N, Scremin E, Tambone C, Tasca A. A single-center study of 100 consecutive patients with localized prostate cancer treated with stereotactic body radiotherapy. BMC Urol 2013; 13: 49. doi: 10.1186/1471-2490-13-49

33. Oliai C, Lanciano R, Sprandio B, Yang J, Lamond J, Arrigo S, et al. Stereotactic body radiation therapy for the primary treatment of localized prostate cancer. J Radiat Oncol 2013; 2: 63-70. doi: 10.1007/s13566-012-0067-2
34. Mantz C. A Phase II trial of stereotactic ablative body radiotherapy for low-risk prostate cancer using a non-robotic linear accelerator and realtime target tracking: Report of toxicity, quality of life, and disease control outcomes with 5-year minimum follow-up. Front Oncol 2014; 4: 279. doi: 10.3389/fonc.2014.00279

35. Chen LN, Suy S, Wang H, Bhagat A, Woo J, Moures R, et al. Patient-reported urinary incontinence following stereotactic body radiation therapy (SBRT) for clinically localized prostate cancer. Radiat Oncol 2014; 9: 148. doi: 10.1186/1748-717X-9-148

36. Anwar M, Weinberg V, Seymour Z, Hsu J, Roach M 3rd, Gottschalk A. Outcomes of hypofractionated stereotactic body radiotherapy boost for intermediate and high-risk prostate cancer. Radiat Oncol 2016; 11: 8. doi: 10.1186/s13014-016-0585-y

37. Hannan R, Tumati V, Xie XJ, Cho LC, Kavanagh B, Brindle J, et al. Stereotactic body radiation therapy for low and intermediate risk prostate cancerResults from a multi-institutional clinical trial. Eur J Cancer 2016; 59: 142-51. doi: 10.1016/j.ejca.2016.02.014

38. Murthy V, Sinha S, Kannan S, Datta D, Das R, Bakshi G, et al. Safety of prostate stereotactic body radiation therapy after Transurethral Resection of Prostate (TURP): A propensity score matched pair analysis. Pract Radiat Oncol 2019; 5: 347-53. doi: 10.1016/j.prro.2019.04.003

39. Wang K, Chen RC, Kane B, Medbery C, Underhill K, Gray J, et al. Patient and dosimetric predictors of genitourinary and bowel quality of life after prostate SBRT: Secondary analysis of a multi-institutional trial. Int J Radiat Oncol Biol Phys 2018; 102: 1430-37. doi: 10.1016/j.jirobp.2018.07.191

40. Bolzicco G, Favretto MS, Satariano N, Scremin E, Tambone C, Tasca A. A single-center study of 100 consecutive patients with localized prostate cancer treated with stereotactic body radiotherapy. BMC Urol 2013; 13: 49. doi: 10.1186/1471-2490-13-49

41. Katz AJ, Kang J. Quality of life and toxicity after SBRT for organ-confined prostate cancer, a 7-year study. Front Oncol 2014; 4: 301. doi: 10.3389/ fonc.2014.00301

42. Gurka MK, Chen LN, Bhagat A, Moures R, Kim SJ, Yung T, et al. Hematuria following stereotactic body radiation therapy (SBRT) for clinically localized prostate cancer. Radiat Oncol 2015; 10: 44. doi: 10.1186/s13014-0150351-6 